\title{
The Opioid System and Brain Development: Effects of Methadone on the Oligodendrocyte Lineage and the Early Stages of Myelination
}

\author{
Allison A. Vestal-Laborde ${ }^{a}$ Andrew C. Eschenroeder ${ }^{a}$ John W. Bigbee ${ }^{b}$ \\ Susan E. Robinson ${ }^{c, d}$ Carmen Sato-Bigbee ${ }^{a}$ \\ Departments of a Biochemistry and Molecular Biology, ${ }^{\mathrm{b}}$ Anatomy and Neurobiology, and ${ }^{\mathrm{C} P h a r m a c o l o g y}$ and \\ Toxicology and ${ }^{d}$ Institute for Drug and Alcohol Studies, Virginia Commonwealth University School of Medicine, \\ Richmond, Va., USA
}

\section{Key Words}

Brain development $\cdot$ Myelination · Myelin .

Oligodendrocytes - Opioid use and myelination .

Opioids and pregnancy . Opioid addiction treatment

\begin{abstract}
Oligodendrocytes express opioid receptors throughout development, but the role of the opioid system in myelination remains poorly understood. This is a significant problem as opioid use and abuse continue to increase in two particular populations: pregnant addicts (in whom drug effects could target early myelination in the fetus and newborn) and adolescents and young adults (in whom late myelination of 'higher-order' regions takes place). Maintenance treatments for opioid addicts include the long-lasting opioids methadone and buprenorphine. Similar to our previous findings on the effects of buprenorphine, we have now found that early myelination in the developing rat brain is also altered by perinatal exposure to therapeutic doses of methadone. Pups exposed to this drug exhibited elevated brain levels of the 4 major splicing variants of myelin basic protein, myelin proteolipid protein, and myelin-oligodendrocyte glycoprotein. Consistent with the enrichment and function of these proteins in mature myelin, analysis of the corpus callosum in these young animals also indicated an elevated number of
\end{abstract}

axons with already highly compacted myelin sheaths. Moreover, studies in cultured cells showed that methadone exerts direct effects at specific stages of the oligodendrocyte lineage, stimulating the proliferation of progenitor cells while on the other hand accelerating the maturation of the more differentiated but still immature preoligodendrocytes. While the long-term effects of these observations remain unknown, accelerated or increased oligodendrocyte maturation and myelination could both disrupt the complex sequence of synchronized events leading to normal connectivity in the developing brain. Together with our previous observations on the effects of buprenorphine, the present findings further underscore a crucial function of the endogenous opioid system in the control of oligodendrocyte development and the timing of myelination. Interference with these regulatory systems by opioid use or maintenance treatments could disrupt the normal process of brain maturation at critical stages of myelin formation.

(c) 2014 S. Karger AG, Basel

\section{Introduction}

Findings from worldwide studies indicate a dramatic increase in drug abuse, with opioid dependence identified as the leading contributor to premature disability and

\section{KARGER}

(C) 2014 S. Karger AG, Basel

0378-5866/14/0365-0409\$39.50/0

E-Mail karger@karger.com

www.karger.com/dne
Carmen Sato-Bigbee

Department of Biochemistry and Molecular Biology

Virginia Commonwealth University School of Medicine

1101 East Marshall Street, Richmond, VA 23298-0614 (USA)

E-Mail csatobig@vcu.edu 
mortality rates [1]. Essential in this regard is the observation that major increases in opioid abuse are found during adolescence and early adulthood, windows of late brain development, the importance of which is underscored by the frequent concomitant onset of psychiatric disease [2, $3]$. This problem is further aggravated by the frequency of opioid use and abuse during pregnancy and the potential effects of opioid maintenance treatments with synthetic long-lasting opioid analogues such as methadone and buprenorphine. While these two drugs represent effective and valuable treatments for pregnant addicts $[4,5]$, both methadone and buprenorphine cross the placenta $[6,7]$, raising the possibility of a variety of early opioid exposure effects on brain maturation and cognitive development that are still poorly understood [8].

One of the most critical processes along brain maturation is the formation of the myelin membrane. The original view of myelin as a lipid-rich structure functionally restricted to axonal insulation and saltatory conduction has been replaced by one of a molecularly intricate and highly dynamic component of the brain. It is now well known that this complex membrane regulates axonal extension and radial growth [9], as well as axolemmal ion channel distribution [10]. Moreover, the myelin-forming oligodendrocytes are involved in electrical coupling to astrocytes [11] and bidirectional glial-neuronal communications [12] and have been identified as critical players in novel support mechanisms of neuronal survival and axonal function and integrity $[13,14]$. Oligodendrocytes are generated from highly proliferative and migratory progenitors that undergo several well-defined stages of differentiation prior to becoming postmitotic mature cells capable of myelination [15-17]. This complex sequence of events is subjected to multiple regulatory mechanisms [reviewed in 18], placing the generation of these cells and myelin formation among the most vulnerable processes during brain development. Importantly, there is increasing evidence to support a crucial function of the endogenous opioid system in myelination. Neural stem cells and cells at different maturational stages along the oligodendroglial lineage express opioid receptors, and their modulation in culture has been shown to induce both mitogenic and differentiating effects [19-22]. These findings raise the possibility that interference with the endogenous opioid system by drug abuse and maintenance treatments for opioid addicts may have an effect on brain myelination.

As the use and abuse of prescription and nonprescription opioids continue to increase among young users [23-26], it is logical to hypothesize that active myelina- tion periods in two main high-risk groups are particularly vulnerable to the effects of these drugs: (1) early myelination in fetuses and newborns from pregnant opioid addicts, and (2) late myelination of 'higher-order' regions in the adolescent and young-adult brain. Heroin and morphine abuse in humans has been linked to neurotoxic effects resulting in leukoencephalopathy and myelin loss [27-30], but little is known regarding the effects on myelin induced by other abused opioids or, equally important, opioid molecules which, like methadone and buprenorphine, are recommended in maintenance treatments for drug abuse. We have shown before that myelination of the maturing rat brain is altered by perinatal exposure to buprenorphine [31], a $\mu$-opioid receptor partial agonist and $\kappa$-opioid receptor antagonist currently in clinical trials for the management of pregnant opioid addicts. While supra-therapeutic doses of this drug delayed myelination, therapeutic doses resulted in accelerated and increased brain expression of myelin basic proteins (MBP), markers of myelin and differentiated oligodendrocytes [31]. The finding of a bell-shaped dose-response curve led us to the discovery of a novel mechanism that controls oligodendrocyte maturation by opposing effects mediated by the $\mu$-opioid and nociceptin/orphanin (nociceptin) FQ (NOP) receptors [22]. Activation of the $\mu$-opioid receptor by low doses of buprenorphine stimulates cell maturation while high buprenorphine levels induce an inhibitory effect on oligodendrocyte differentiation mediated by the NOP receptor. Interestingly, that study used methadone as a control for $\mu$-opioid receptor activity and indicated that, similar to the low doses of buprenorphine, exposure of oligodendrocytes to methadone resulted in increased MBP expression. That initial clue suggested that myelination could also be directly affected by methadone, a problem of significant importance as this synthetic opioid is currently used in opioid detoxification treatments for pregnant addicts and their newborns [32]. We now report that, at least in the rat brain, early myelination is indeed altered by perinatal exposure to therapeutic levels of methadone. Pups exposed to methadone had increased brain levels of MBP, myelin proteolipid protein (PLP), and myelin-oligodendrocyte glycoprotein (MOG), and, in agreement with the known enrichment of these proteins in mature myelin, these young animals also exhibited an elevated number of axons with already highly compacted myelin sheaths. Furthermore, studies on cultured cells indicated that methadone exerts direct effects at specific stages of oligodendrocyte development inducing proliferation of the progenitor cells while on the other hand stimulating the 
maturation of the more differentiated but still immature preoligodendrocytes. Far from being beneficial, accelerated or increased oligodendrocyte maturation and myelination could both potentially disrupt normal connectivity in the developing brain. Together with our previous observations on the effects of buprenorphine, these results provide further evidence for an important role of the endogenous opioid system in the timing of oligodendrocyte differentiation and myelin formation. Alteration of these regulatory systems by opioid use or related treatments could disrupt the normal process of brain maturation at critical stages of myelination.

\section{Methods}

\section{Perinatal Exposure to Methadone}

Animal use for all procedures in this study was in accordance with the guidelines of the National Institutes of Health and was approved by the Virginia Commonwealth University Animal Care and Use Committee. Timed-pregnant Sprague-Dawley rats were from Harlan Laboratories (Indianapolis, Ind., USA). Rat pups were exposed to methadone both during pregnancy and postnatal development as previously reported [33], with minor modifications. On gestation day 7 , pregnant rats were subcutaneously implanted with 28-day Model 2ML4 Alzet osmotic minipumps (Durect, Cupertino, Calif., USA) to deliver methadone $(9 \mathrm{mg} / \mathrm{kg} /$ day) or saline solution (vehicle control). Pups were sacrificed on postnatal days 11 and 19 for analysis of MBP brain expression by western blotting and on postnatal day 16 for visualization of myelin formation by electron microscopic examination as indicated below.

\section{Assessment of in vivo Myelination by Electron Microscopy}

Brain samples for the analysis of myelinated axons were prepared from 16-day-old rat controls or rats exposed to methadone as indicated above. For this, pups were anesthetized by intraperitoneal injection of $2.5 \%$ Avertin and transcardially perfused with $4 \%$ paraformaldehyde and $2.5 \%$ glutaraldehyde in $10 \mathrm{~mm}$ $\mathrm{Na}_{2} \mathrm{HPO}_{4}, 2.7 \mathrm{mM} \mathrm{KCl}$, and $137 \mathrm{mM} \mathrm{NaCl}, \mathrm{pH}$ 7.4 (PBS). Brains were removed and maintained overnight in $4 \%$ paraformaldehyde and $2.5 \%$ glutaraldehyde. The tissue was then postfixed with $1 \%$ osmium tetroxide in $100 \mathrm{~mm}$ cacodylate buffer, $\mathrm{pH} 7.3$, and plastic embedded. Thin sagittal sections of the region containing the middle portion of the body of the corpus callosum were stained with uranyl acetate and lead citrate and then examined using a Jeol JEM-1230 transmission electron microscope. Fifteen contiguous fields of each section were photographed at a $\times 5,000$ magnification comprising approximately $250 \mu \mathrm{m}^{2} /$ field. A minimum of 4 animals/group, with equal numbers of males and females from different litters, were analyzed. At least 5,000 axons were analyzed for each animal treatment and grouped into 3 categories according to their stage of myelination ( $\leq 4$ myelin membrane wraps, uncompacted myelin, and compacted myelin) as further described in Results and figure 3. Myelin thickness for the compacted myelin group was evaluated by analysis of ' $G$ ratios' calculated as the ratio of 'diameter of axon alone' to 'diameter of axon + myelin'.
Isolation and Culture of Oligodendrocytes

Oligodendrocytes were isolated from either 3-day-old (oligodendrocyte progenitors) or 9-day-old (preoligodendrocytes) Sprague-Dawley rat brains using a Percoll gradient (GE Healthcare Bio-Sciences, Pittsburgh, Pa., USA) and differential adhesion as previously reported $[22,34]$. Briefly, brain meninges and main blood vessels were removed by gently rolling the tissue on sterile filter paper. After mincing into about $2-\mathrm{mm}$ pieces, the tissue was subjected to dissociation by incubation on a rocking platform for $25 \mathrm{~min}$ at $37^{\circ} \mathrm{C}$ in the presence of $1 \mathrm{unit} / \mathrm{ml}$ papain and $0.01 \mathrm{mg} /$ ml DNAse (Sigma-Aldrich, St. Louis, Mo., USA). After extensive washing and filtration through a $75 \mu \mathrm{M}$ pore size nylon mesh (Sefar, Depew, N.Y., USA), the cell suspension was centrifuged for 15 $\min$ at $30,000 \times g$ in an isotonic self-generated Percoll (Sigma-Aldrich) gradient. The fraction enriched in oligodendrocytes was then subjected to differential adhesion on a tissue culture-treated Petri dish to eliminate the microglial cells and residual astrocytes. The floating oligodendrocytes were subsequently plated in 48-well plates (for western blots and MBP gene promoter experiments) or 8-well slide Permanox chambers (Thermo Fischer Scientific) (for analysis by immunocytochemistry), all previously coated with $12.5 \mu \mathrm{l} /$ well of growth factor-reduced Matrigel ${ }^{\mathrm{TM}}$ extracellular matrix (Becton Dickinson, Franklin Lakes, N.J., USA). Cells were maintained in chemically defined medium (CDM) [Dulbecco's modified Eagle's medium/Ham F-12 (DMEM/F12) (1:1) medium with high glucose and L-glutamine (GIBCO-Life Technologies, Grand Island, N.Y., USA), pH 7.4, supplemented with $1 \mathrm{mg} / \mathrm{ml}$ fatty acid-free bovine serum albumin, $50 \mu \mathrm{g} / \mathrm{ml}$ transferrin, $5 \mu \mathrm{g}$ / $\mathrm{ml}$ insulin, $30 \mathrm{nM}$ sodium selenite, $1 \mathrm{~mm}$ sodium pyruvate, $10 \mathrm{nM}$ biotin, $20 \mathrm{nM}$ progesterone, $100 \mu \mathrm{M}$ putrescine, and $30 \mathrm{nM}$ triiodothyronine (Sigma-Aldrich)]. Cultures were maintained in a humidified incubator at $37^{\circ} \mathrm{C}$ in $5 \% \mathrm{CO}_{2}$.

\section{Western Blot Analysis}

For protein analysis in cell lysates, cultured cells were directly solubilized in $75 \mu \mathrm{l}$ of $2 \times$ Laemmli sample buffer [ $65.8 \mathrm{mM}$ Tris$\mathrm{HCl}, \mathrm{pH} 6.8,2.1 \%$ sodium dodecylsulfate sulfate, $26.3 \%$ (w/v) glycerol, $0.01 \%$ bromophenol blue, and $5 \% \beta$-mercaptoethanol]. For protein analysis in tissue samples, rat brains were rapidly removed, frozen in liquid nitrogen, and maintained at $-80^{\circ} \mathrm{C}$ until homogenization in PBS supplemented with a protease inhibitor cocktail (Sigma-Aldrich) and appropriate dilution in Laemmli buffer. Boiling of Laemmli buffer-solubilized samples for PLP analysis as well as freezing and defrosting of samples for MBP were avoided to preclude the loss of bands by formation of high-molecular-weight aggregates. Proteins were then separated by sodium dodecylsulfate sulfate-polyacrylamide gel electrophoresis in $12 \%$ acrylamide gels and electro-transferred to nitrocellulose as before [35]. All electrophoresis reagents and supplies were from Bio-Rad Laboratories (Hercules, Calif., USA). The membranes were then subjected to western blot analysis as previously reported [22], using the following primary antibodies: anti-MBP (Millipore, Temecula, Calif., USA, raised against peptide $82-87$, dilution $1: 100$ ), anti-MOG (Millipore, dilution 1:2,000), anti-PLP (Abcam Inc., Cambridge, Mass., USA, dilution 1:1,000), or anti- $\beta$-actin (Sigma-Aldrich, dilution 1:5,000). After incubation with the appropriate horseradish peroxidase-conjugated secondary antibodies, immunoreactive bands were detected by chemiluminescence reaction with Super Signal West Dura reagent (Thermo Scientific, Rockford, Ill., USA). The relative expression levels of the immunoreactive bands were 
determined by scanning densitometric analysis of the X-ray films using the NIH Image J program. MBP, MOG, and PLP levels for each sample were divided by the corresponding $\beta$-actin values to correct for protein loading differences.

\section{Immunocytochemistry}

Oligodendrocyte cultures were fixed for $20 \mathrm{~min}$ with $4 \%$ paraformaldehyde in PBS and double immunocytochemical staining was carried out as reported before [22], with minor modifications. Nonspecific antibody binding was blocked by incubation for $1 \mathrm{~h}$ in PBS with $0.5 \%$ normal goat serum and $0.05 \%$ Tween-20 (blocking solution). Cell cultures were then subjected to overnight incubation with a mixture of rat IgG anti-MBP (Millipore, dilution 1: 20) and mouse IgM O4 (dilution 1:3) monoclonal antibodies in blocking solution. The $\mathrm{O} 4$ hybridoma supernatant was kindly provided by Dr. Babette Fuss (Virginia Commonwealth University). After washing, cells were incubated for $30 \mathrm{~min}$ in blocking solution and for $2 \mathrm{~h}$ with a mixture of Texas red-conjugated anti-rat IgG (dilution 1:150) and Alexa-488-conjugated anti-mouse IgM (dilution 1:150) (Jackson ImmunoResearch Laboratories, West Grove, Pa., USA). Cell staining was analyzed using a Nikon Eclipse 800M fluorescence microscope and digital camera system.

\section{MBP Gene Promoter Reporter Assay}

One day after isolation from 9-day-old rat brains, cells were transfected with a construct containing the MBP gene sequence from $-1,323$ to +30 upstream of the firefly luciferase-coding region in a pGL3Basic vector (kindly provided by Dr. Robin Miskimins, University of South Dakota), as we previously reported [36], with minor modifications. For this, $80 \%$ confluent cell cultures in 48 well plates were incubated for $3 \mathrm{~h}$ in $250 \mu \mathrm{l}$ DMEM/F12 medium alone containing a mixture of $0.8 \mu \mathrm{g}$ firefly luciferase-MBP gene promoter construct, $0.03 \mu \mathrm{g}$ of a renilla luciferase vector (Promega, Madison, Wisc., USA) used as a control for both sample size and transfection efficiency ( 25\%), and $1.2 \mu \mathrm{l}$ GeneJammer transfection reagent (Stratagene, La Jolla, Calif., USA). At the end of the incubation period, the transfection medium was removed and the cultures were carefully rinsed with DMEM/F12 medium alone and then maintained overnight in complete CDM as indicated above for the culture of oligodendrocytes. The cultures were then incubated for $24 \mathrm{~h}$ in CDM with or without $0.5 \mu \mathrm{M}$ methadone. At the end of the treatment, the medium was removed and the cells were lysed by addition of $100 \mu$ Passive Lysis buffer (Promega) and the plates were immediately frozen overnight at $-80^{\circ} \mathrm{C}$, followed by fast thawing and harvesting of the lysates. After $30 \mathrm{~s}$ of centrifugation at 10,000 rpm, the supernatants were collected and assayed for firefly and renilla luciferase activities using the Dual-Luciferase Reporter Assay System (Promega), following the manufacturer's recommendations. The relative MBP gene promoter activities for each sample were calculated as the ratio of firefly to control renilla luciferase luminescence readings.

\section{$\left.{ }^{3} \mathrm{H}\right]$ Thymidine Incorporation}

Assessment of cell proliferation by $\left[{ }^{3} \mathrm{H}\right]$ thymidine incorporation into DNA was carried out as previously reported [37], with minor modifications. One day after isolation from 3-day-old rat brains as indicated above, oligodendrocyte progenitor cells plated in 48 -well plates were incubated in CDM containing $3 \mu \mathrm{Ci} / \mathrm{ml}\left[{ }^{3} \mathrm{H}\right]$ thymidine $(75 \mathrm{Ci} / \mathrm{mmol}$ specific activity; Amersham Biosciences, Piscataway, N.J., USA) in the presence or absence of different con- centrations of methadone. After $24 \mathrm{~h}$, the radioactive medium was removed and the cultures were carefully washed 3 times with icecold PBS, followed by lysis of the cells and protein-DNA precipitation by addition of $250 \mu \mathrm{l} /$ well of $20 \%$ trichloroacetic acid and incubation for $30 \mathrm{~min}$ at $4^{\circ} \mathrm{C}$. The culture wells were then subjected to 3 additional 15 -min washes with ice-cold $10 \%$ trichloroacetic acid to eliminate any potentially remaining free $\left[{ }^{3} \mathrm{H}\right]$ thymidine. Finally, the protein/DNA precipitate attached to the plates was solubilized by addition of $100 \mu \mathrm{l} /$ well of $70 \%$ formic acid and incubation of the Parafilm-sealed culture plates for $1 \mathrm{~h}$ at $37^{\circ} \mathrm{C}$. The content of each well and the additional $50 \mu \mathrm{l}$ formic acid used for rinsing were both transferred to a vial and used to determine the radioactivity incorporated into the DNA by liquid scintillation counting.

\section{Statistical Analysis}

Statistical analysis was performed by one-way analysis of variance and an unpaired t test using the Prism $6.0 \mathrm{v}$ program (GraphPad Software, La Jolla, Calif., USA). $\mathrm{p}<0.05$ was considered statistically significant.

\section{Results}

As indicated before, our previous findings on the effects of buprenorphine $[22,31]$ raised the possibility that myelination may also be altered by perinatal exposure to methadone. To investigate this possibility, pregnant rats at gestational day 7 were implanted with 28 -day osmotic minipumps to deliver methadone at a dose of $9 \mathrm{mg} / \mathrm{kg} /$ day. By using this experimental paradigm, pups were initially exposed to this opioid through the placenta and then through maternal milk until postnatal day 14 , a neurodevelopmental period that is equivalent to the third trimester in human pregnancy [38]. It is also important to consider that the methadone clearance (CL) and volume of distribution $\left(\mathrm{V}_{\mathrm{d}}\right)$ in the rat $\left(\mathrm{CL}=59.3, \mathrm{~V}_{\mathrm{d}}=7.58\right)$ are significantly higher than in humans $\left(\mathrm{CL}=1.4, \mathrm{~V}_{\mathrm{d}}=3.8\right)$ [39]. Thus, the level of drug exposure used in this study is at the lowest end of the dose range administered to pregnant women (30-110 mg/day) [40].

The two age groups initially investigated were selected as representative of the initiation (postnatal day 11) and the most active (postnatal day 19) stages of rat brain myelination. As a first step, the brains were screened for potential effects of methadone on the expression levels of MBPs (proteins generated by alternative splicing of a single gene that is subjected to developmental regulation) [41]. Importantly, MBPs constitute $30 \%$ of the total myelin proteins and are considered to be specific markers of mature oligodendrocytes [42] and required for myelin compaction [43]. Surprisingly, western blot analysis at both developmental stages indicated that the brains of pups ex- 


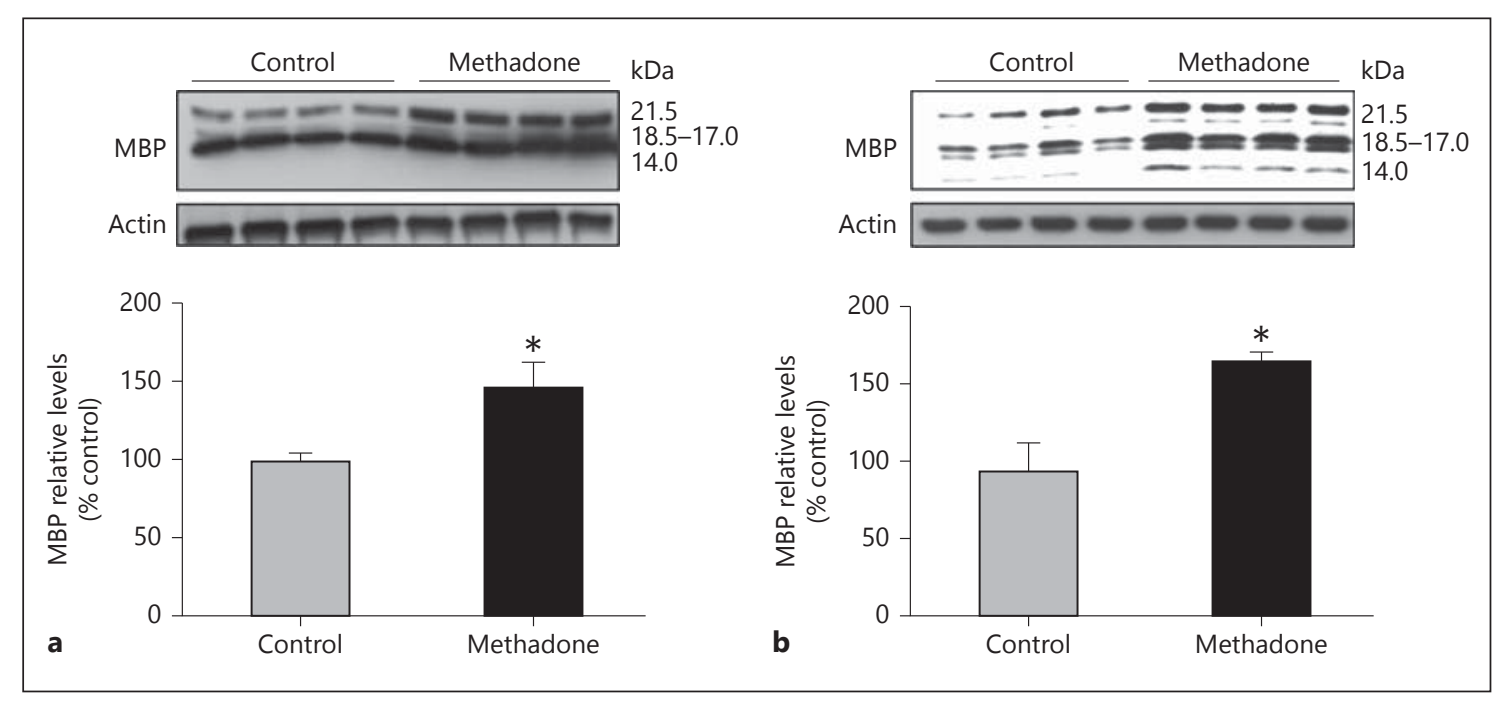

Fig. 1. Perinatal exposure to methadone resulted in elevated MBP brain expression. Perinatal exposure to methadone was carried out as indicated under Methods. The relative expression levels of the 14-, 17-, 18.5-, and 21.5-kDa MBP splicing variants were analyzed in total brain homogenates at postnatal days 11 (a) and 19 (b). Representative western blots are shown. The results in the bar graphs are means \pm SEM from at least 15 brains from 3 different litters/group. Each of the individual values corresponds to com-

posed to methadone contained abnormally elevated levels of the 4 major MBP splicing variants, with values about $50 \%$ higher than those in the corresponding age-matched controls (fig. 1). Further analysis of the brains for other proteins characteristic of mature myelin indicated that the effects of methadone were not simply restricted to the MBPs. As shown in figure 2, increased expression at both ages was also observed for PLP (fig. 2a), a proteolipid that contributes to nearly $50 \%$ of the total myelin protein [44], and for MOG (fig. 2b), a glycoprotein highly enriched in the late outermost lamellae of the myelin sheath [42].

The elevated levels of MBP, PLP, and MOG raised the possibility of increased myelin synthesis. Thus, we next examined the brains of 16-day-old pups for potential effects of methadone on myelination. Electron microscopic examination of the corpus callosum was used to assess the stage of myelin formation in individual axons that were accordingly classified within one of the following categories: axons at the initial stage of myelination, as represented by the presence of no more than 4 loose wraps of membrane (fig. 3a); axons at intermediate stages of myelin formation, as indicated by the presence of more than 4 but still uncompacted membrane wraps (fig. 3b), and axons with already compacted myelin sheaths (fig. 3c). As shown in figure $4 a$, a significant number of

Opioids, Methadone, Oligodendrocytes, and Myelination bined scanning of the $4 \mathrm{MBP}$ isoforms. $\beta$-Actin levels were used as loading controls. Control vs. methadone: 11 days, ${ }^{*} \mathrm{p}<0.03 ; 19$ days, $* \mathrm{p}<0.05$. Notice that the intensity of the bands between both ages is not comparable as film exposure times were adjusted to maintain linear detection of the immunoreactivity. Also note that the $14-\mathrm{kDa}$ isoform is barely detected at 11 days but significantly increases in the more mature brains at 19 days of age.

axons within each category coexist at this early stage of development in both controls and methadone-exposed pups. Remarkably, while a comparison between the controls and the methadone-treated animals failed to detect any significant differences in the number of axons within the first two categories, pups exposed to methadone exhibited a $20 \%$ increase in the number of axons with highly compacted myelin sheaths (fig. 4b). Analysis of G ratios for axons within this category indicated, however, similar correlations between myelin thickness and axonal caliber in both experimental groups (fig. 4c).

The finding of increased MBP, PLP, and MOG levels, together with the elevated number of mature myelinated axons, was consistent with a stimulatory effect of methadone on early myelination. Nevertheless, the larger number of axons with compacted myelin in the methadoneexposed pups was not accompanied by a parallel decrease in the number of axons at earlier stages of myelination, a situation that one would logically expect if myelin maturation were simply accelerated. This intriguing observation suggested the existence of complex effects of methadone on myelin formation and perhaps oligodendrocyte development.

To better investigate the potential effects of methadone on oligodendrocytes, we next decided to explore the 


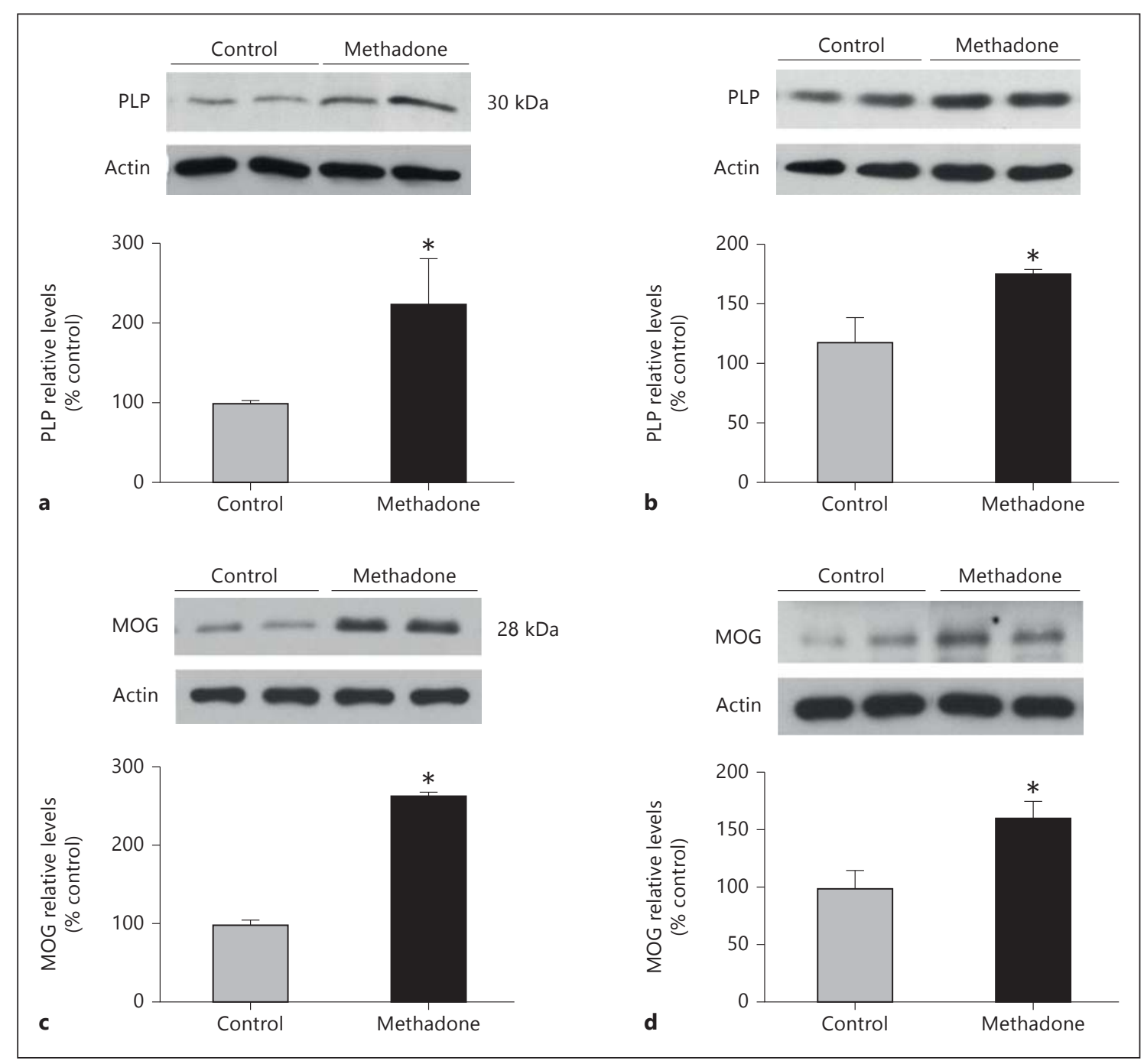

Fig. 2. Pups exposed to methadone also exhibited increased brain levels of PLP and MOG. Pups were perinatally exposed to methadone as described under Methods. Total brain homogenates from 11- (a, c) and 19-day-old rats (b, d) were analyzed for PLP (a, b) and MOG $(\mathbf{c}, \mathbf{d})$ expression by Western blot analysis with the re-

possibility of direct drug effects at different stages of cell maturation. For these studies, cultures were prepared using cells directly isolated from rat brains at different postnatal ages. It is expected that these cells are at the time of plating, more representative of in vivo oligodendrocytes than those induced to differentiate for extensive periods of time in culture. Cells isolated from 3-day-old rat brains are immature oligodendrocyte progenitors that are bipolar or exhibit few simple processes and can be labeled with the A2B5 antibody. On the other hand, cells obtained from 9-day-old animals are already preoligodendrocytes that react with the $\mathrm{O} 4$ antibody but do not yet express spective antibodies. Representative Western blots are shown. Each value presented in the bar graphs corresponds to the mean \pm SEM from at least 10 brains from 3 different litters/group. $\beta$-Actin levels were used as loading controls. Control vs. methadone: ${ }^{*} \mathrm{p}<0.03$.

MBP [34, 45]. These later cells represent a crucial developmental stage that immediately precedes the generation of mature oligodendrocytes capable of myelination. We first investigated the potential proliferative effects of methadone on oligodendrocyte progenitors since earlier studies had shown that $\mu$-opioid receptor activation could increase the mitogenic capacity of these still immature cells $[19,46]$. In agreement with this possibility, exposure of the oligodendrocyte progenitors from 3-day-old rat brains to methadone indeed resulted in a significant increase in $\left[{ }^{3} \mathrm{H}\right]$ thymidine incorporation into their DNA (fig. 5), an observation that indicated a direct stimulation 

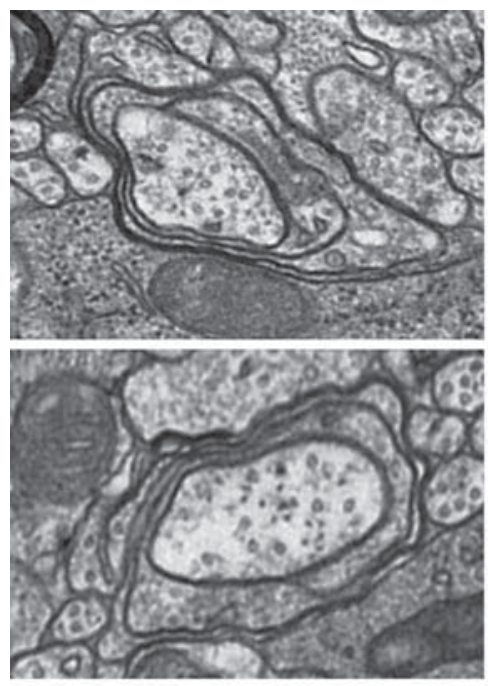

a
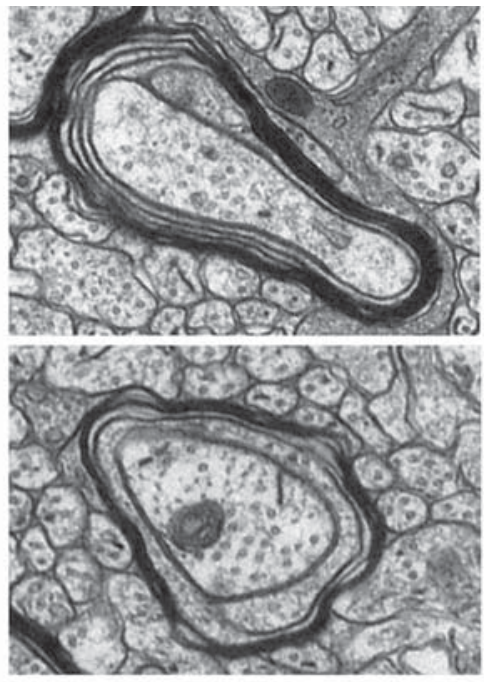

b

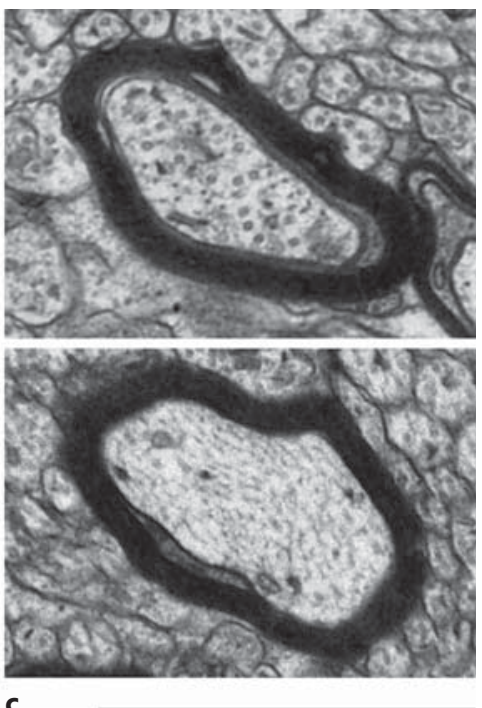

c
Fig. 3. Classification of axons according to their stage of myelination. Brain samples for the analysis of myelinated axons were prepared from 16-day-old pups, and thin sections of the region containing the mid body of the corpus callosum were examined by electron microscopy as described in Methods. Samples were photographed at a $\times 5,000$ magnification and axons were classified within the following 3 categories: axons at the initial stage of my-

of methadone on cell proliferation. Notice that, while the proliferation of oligodendrocyte progenitors was significantly stimulated at 0.5 and $1 \mu \mathrm{M}$ methadone, the stimulation was not observed at the $3 \mu \mathrm{M}$ concentration. At this dose, cultures exhibited proliferation values that were lower than at either 0.5 or $1 \mu \mathrm{M}$ drug concentrations but were not significantly different from those in the control cultures. This lack of an effect at $3 \mu \mathrm{M}$ methadone does not seem to result from a deleterious effect on the cells since we were unable to detect increased cell death or apoptosis (data not shown). However, it may reflect receptor desensitization as elevated levels of methadone induce desensitization and internalization of the $\mu$-opiod receptor in neurons [47].

In addition to the proliferative effects, the elevated brain levels of MBP, PLP, and MOG, together with the augmented number of axons with already compacted myelin sheaths, also pointed to a parallel stimulatory effect of methadone on oligodendrocyte maturation. In support of this possibility, our previous studies on the effects of buprenorphine used methadone as a control for $\mu$-opioid receptor activity and indicated that incubation of preoligodendrocytes with $1 \mu \mathrm{M}$ methadone resulted in increased MBP expression [22]. Importantly, we have now found that a positive effect is also observed at even elination (a), as represented by the presence of no more than 4 loose wraps of membrane; axons at intermediate stages of myelin formation (b), as indicated by the presence of more than 4 but still uncompacted membrane wraps, and axons with already compacted myelin sheaths $(\mathbf{c})$. Scale bar $=1 \mu \mathrm{m}$. Photos were taken from samples corresponding to the control animals. much lower doses of methadone and extends to different markers of oligodendrocyte maturation. As shown in figure $6 \mathrm{a}$, cells at the preoligodendrocyte stage are highly responsive to methadone, already exhibiting a significant elevation of MBP levels in the presence of drug concentrations as low as $0.1 \mu \mathrm{M}$.

In addition, experiments in which preoligodendrocyte cultures were transfected with a luciferase-reporter construct driven by the MBP gene promoter showed that the methadone-induced increase in MBP protein expression was preceded by a parallel enhancement of MBP gene activity (fig. 6b). Furthermore, as shown in figure $6 c$, treatment of the cultures with methadone at this developmental stage also resulted in a significant increase in the expression of MOG, a molecule that, as indicated above, is highly enriched in the late outermost lamellae of the myelin sheath [42] and is therefore considered to be a marker of highly mature oligodendrocytes. A positive direct effect of methadone on oligodendrocyte maturation was further indicated by experiments in which the cells were subjected to double immunocytochemical staining with $\mathrm{O} 4$ and anti-MBP antibodies. The $\mathrm{O} 4$ antibody labels both preoligodendrocytes and mature oligodendrocytes, while only mature cells are positive for the presence of MBP. As shown in figure 5d, 3-day exposure of preoligo- 


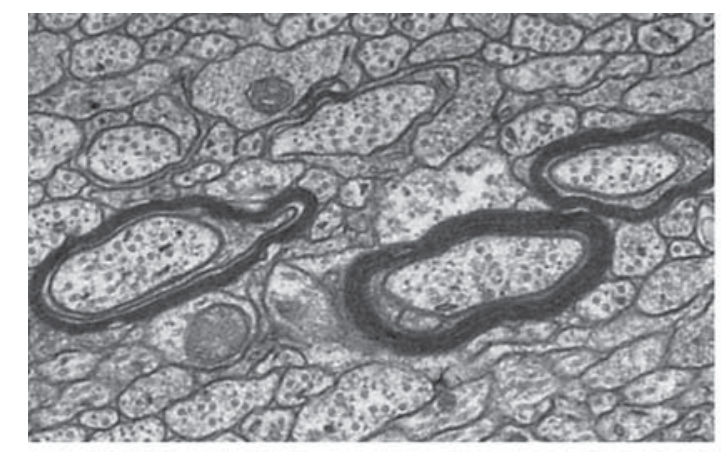

a Control

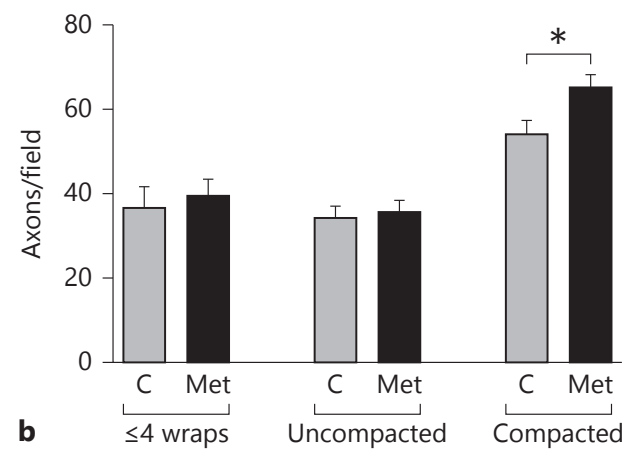

Fig. 4. Perinatal exposure to methadone alters the distribution of axons at different stages of myelination. a Corpus callosum sections from 16-day-old pups were analyzed by EM and classified within 3 different categories as indicated in the legend to figure 3, i.e. axons at the initial stage of myelination, axons at intermediate stages of myelin formation $(\mathrm{C}=\mathrm{Control}$; Met $=$ methadone $)$, and axons with already compacted myelin sheaths. Scale bar $=1 \mu \mathrm{m}$. Notice that axons within the 3 categories coexist in the samples

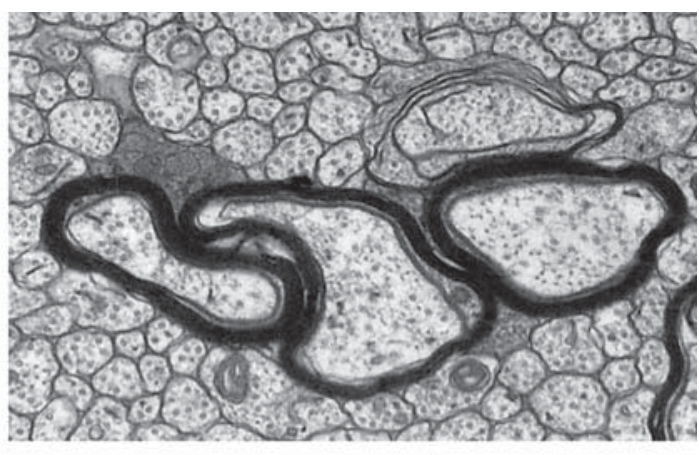

Methadone

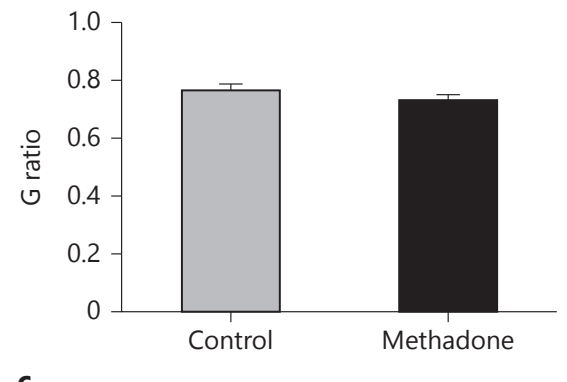

from both methadone-exposed and controls pups. b The bar graph indicates the number of axons/field from each category, shown as the mean \pm SEM from at least 12 fields/pup and a total of 5,000 axons/experimental group; $(\mathrm{C}=\mathrm{Control}$; Met $=$ methadone $){ }^{*} \mathrm{p}<$ 0.05 . $\mathrm{c} G$ ratios for axons within the $\mathrm{c}$ category (compacted myelin) were calculated from the corresponding myelinated axons and fiber diameters ( $G$ ratio: diameter of axon alone/diameter of axon + myelin).
Fig. 5. Treatment of oligodendrocyte progenitors with methadone results in increased cell proliferation. Oligodendrocyte progenitors were isolated from 3-day-old rat brains as indicated under Methods. One day after isolation, the cells were incubated for $24 \mathrm{~h}$ in CDM supplemented with $\left[{ }^{3} \mathrm{H}\right]$ thymidine in the presence or absence of different concentrations of methadone. Cell proliferation was evaluated by measuring $\left[{ }^{3} \mathrm{H}\right]$ thymidine incorporation into the DNA. The results are expressed as percentages of the control values \pm SEM from at least 3 different experiments. ${ }^{*} \mathrm{p}<0.005$, control vs. $3.0 \mu \mathrm{M}$, not significant.

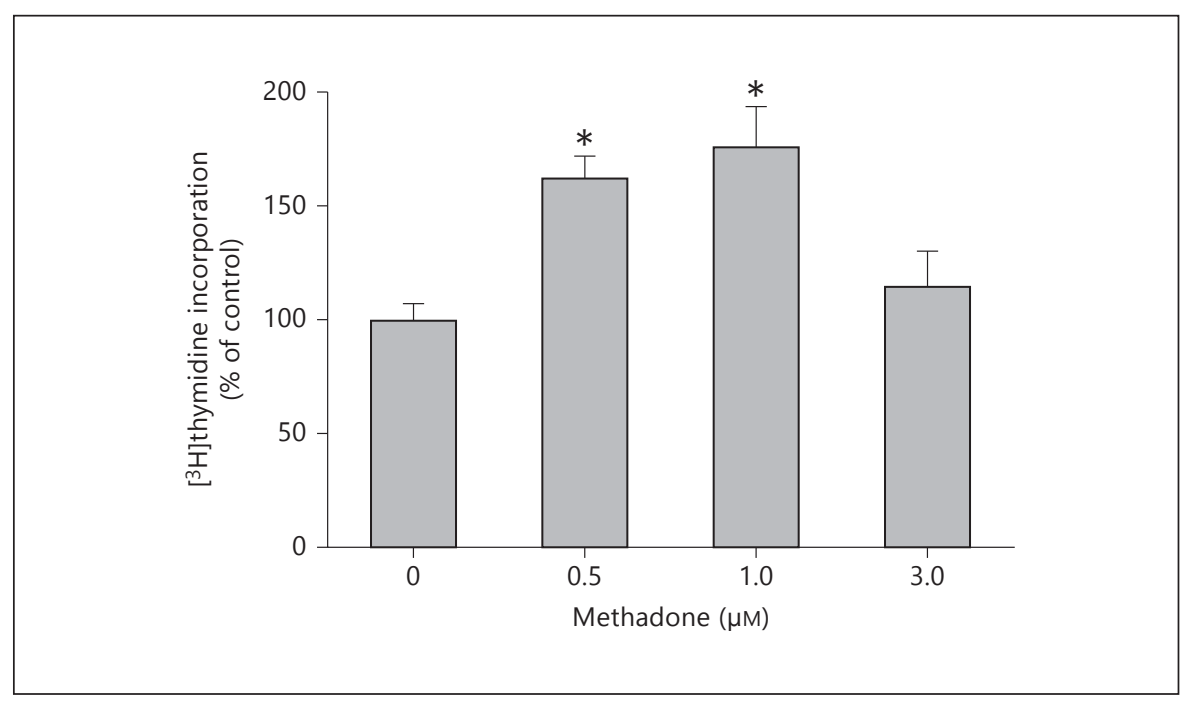

Vestal-Laborde/Eschenroeder/Bigbee/ Robinson/Sato-Bigbee 

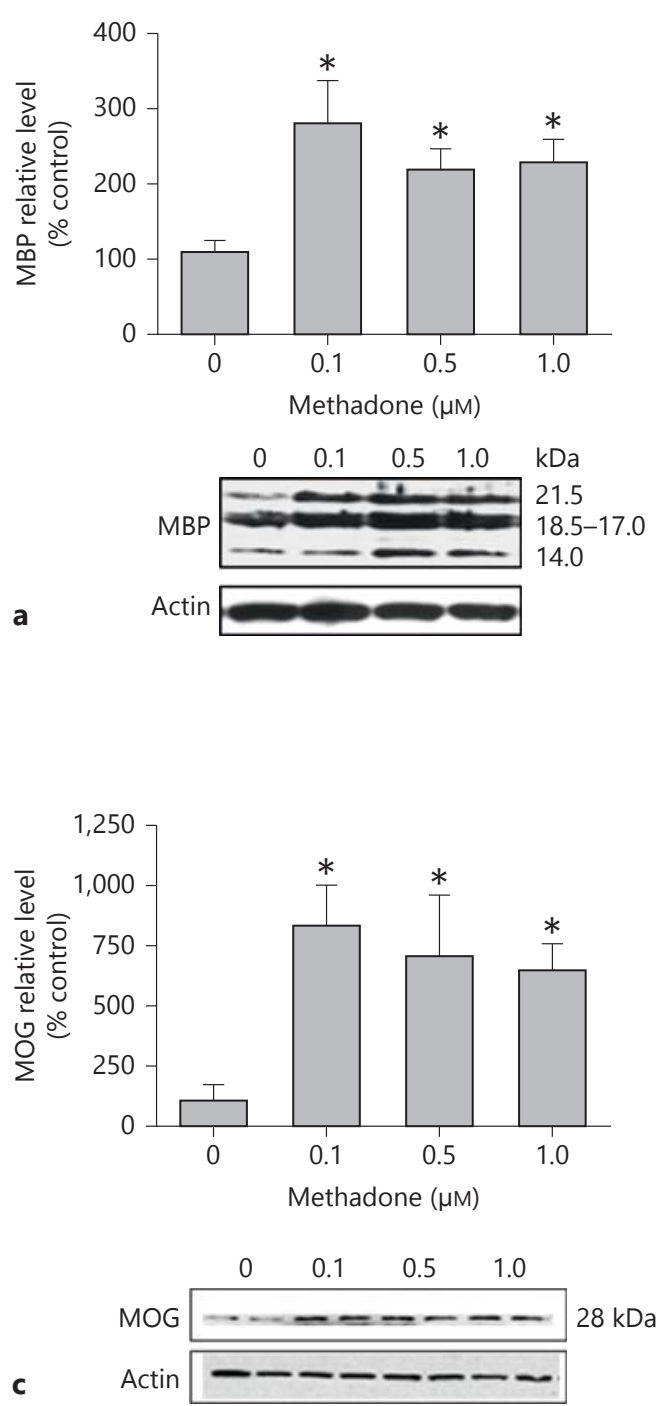
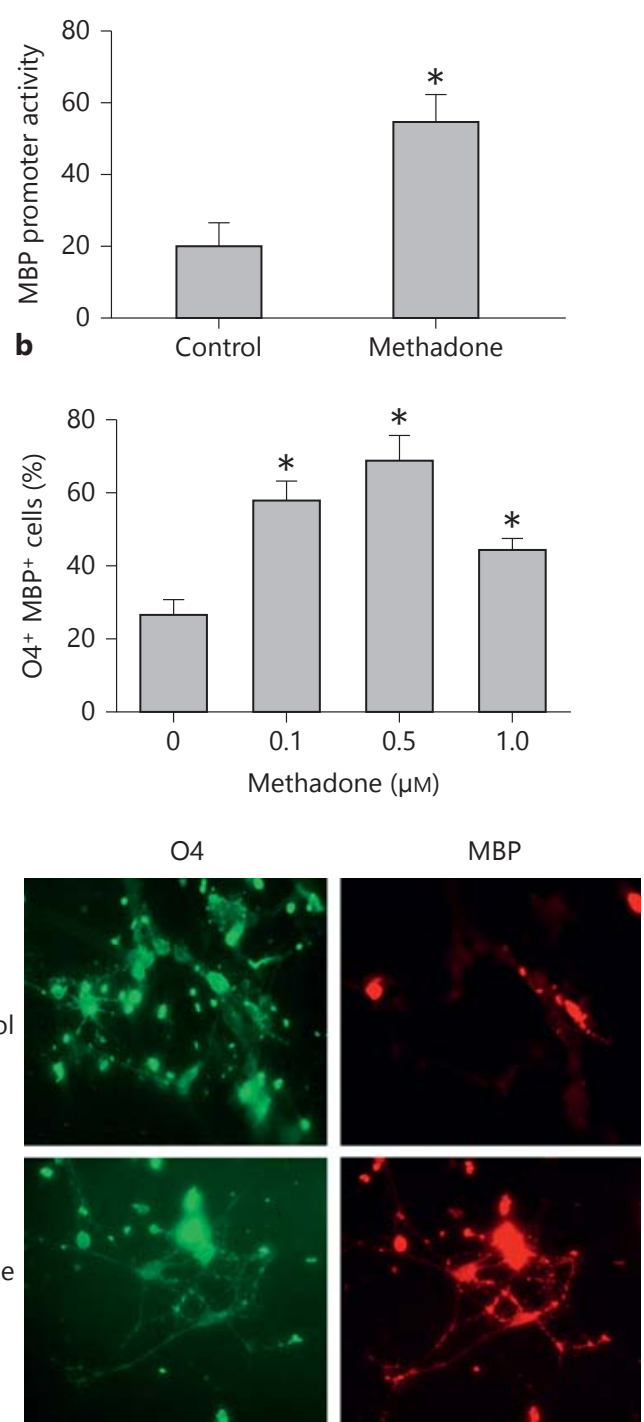

Fig. 6. Methadone stimulates the differentiation of preoligodendrocytes. a Pre-oligodendrocytes isolated from 9-day-old rat brains were incubated for 3 days in CDM with or without $0.1,0.5$, or $1.0 \mu \mathrm{M}$ methadone. MBP levels were determined by western blotting using $\beta$-actin levels as loading controls. The figure corresponds to a representative experiment. Results in the bar graph are expressed as percentages of the controls $(0 \mu \mathrm{M}$ methadone $) \pm$ SEM from at least 5 experiments and correspond to combined scanning of the 4 major MBP isoforms; 0 vs. $0.1 \mu \mathrm{M},{ }^{*} \mathrm{p}<0.02 ; 0$ vs. $0.5 \mu \mathrm{M}$, ${ }^{*} \mathrm{p}<0.002 ; 0$ vs. $1.0 \mu \mathrm{M},{ }^{*} \mathrm{p}<0.005 ; 0.1$ vs. 0.5 vs $1.0 \mu \mathrm{M}$, not significant. b Preoligodendrocytes were cotransfected with a firefly luciferase construct under control of the MBP gene promoter and a renilla luciferase vector used as a sample size and transfection control. After $24 \mathrm{~h}$ in the presence of $0.5 \mu \mathrm{M}$ methadone, the cells were assayed for firefly and renilla luciferase activities. Relative
MBP promoter activities were calculated as ratios of firefly to control renilla luciferase luminescence readings. The values represent means \pm SEM from 3 separate experiments. ${ }^{*} \mathrm{p}<0.03$. c Preoligodendrocytes were incubated for 3 days in CDM with or without $0.1,0.5$, or $1.0 \mu \mathrm{M}$ methadone as indicated in a and MOG levels were determined by western blotting using $\beta$-actin levels as loading controls; 0 vs. $0.1,0.5$, and $1.0 \mu \mathrm{M},{ }^{*} \mathrm{p}<0.05$. d Preoligodendrocytes were cultured for 3 days in CDM alone (control) or supplemented with $0.1,0.5$, or $1.0 \mu \mathrm{M}$ methadone. Cells were analyzed by double immunocytochemistry with $\mathrm{O} 4$ (green) and anti-MBP (red) antibodies. The bar graph indicates the percentage of $\mathrm{O} 4$ positive cells that were also MBP positive under each experimental condition. The results represent the average \pm SEM of 3 different experiments; 0 vs. $0.1,0.5$, and $1.0 \mu \mathrm{M},{ }^{*} \mathrm{p}<0.0 ; 0.1$ vs. 0.5 vs 1.0 $\mu \mathrm{M}$, not significant. 
dendrocytes to methadone resulted in about $70 \%$ of the cells being reactive to both $\mathrm{O} 4$ and anti-MBP antibodies. In contrast, most $\mathrm{O} 4$-positive cells in the control cultures still remained MBP negative.

Altogether, the present observations showed that exposure to methadone could affect developmental brain myelination by exerting specific effects along different stages of oligodendrocyte maturation.

\section{Discussion}

This study found that perinatal exposure to methadone alters the pattern of early myelination in the developing rat brain. Pups exposed to this drug showed elevated brain levels of MBP, PLP, and MOG and, in agreement with the known enrichment of these proteins in mature myelin, these young animals also exhibited an increased number of axons with already highly compacted myelin sheaths. Interestingly, the lack of a parallel reduction in the number of axons with a still uncompacted myelin membrane also pointed to the existence of complex drug effects. In support of this possibility, the studies using cells isolated from the rat brain at different postnatal ages indicated that methadone directly affects the successive stages of oligodendrocyte maturation, specifically increasing the proliferation of progenitor cells while on the other hand promoting the differentiation of the more advanced but still immature preoligodendrocytes. Though still premature, it is tempting to hypothesize that in methadone-exposed pups the abnormal proportion of mature and immature myelin sheaths may reflect the specific drug actions on coexisting pools of oligodendrocytes at different stages of development. If this is the case, the increased number of mature myelin sheaths may be the result of a direct stimulatory effect on oligodendrocyte differentiation. At the same time, the lack of a parallel decrease in still maturing myelin internodes may reflect the late activity of a pool of progenitors with an extended window of cell proliferation and thus delayed differentiation and myelinating capacity. It also remains to be determined what extent of myelination would be attained when animals perinatally exposed to methadone finally reach an adult age and whether long-term studies could additionally detect gender-related differences in drug effects. In this regard, it is important to point out that the present findings are reported as pooled results from an equal number of male and female pups, as we failed to detect any significant sex-dependent differences. However, previous studies have reported sex-related varia- tions in opioid responses [reviewed in 48] as well as sexual dimorphism in rodent oligodendrocytes and white matter [reviewed in 49]. Therefore, we cannot discard the possibility that such sex-related differences may manifest at later stages of development.

Long-term consequences of perinatal drug effects on myelination and extrapolation of the present findings to potential implications in humans are difficult at this time. Reduced myelination was suggested by a study in which diffusion tension imaging was used to examine the superior longitudinal fasciculus in the brains of 13 infants born to methadone-maintained mothers [50]. However, while very important, the extent to which that finding could be directly ascribed to methadone remained to be clarified as the majority of the methadone-exposed babies were also treated with morphine to mitigate neonatal abstinence syndrome, and other confounding factors including general maternal health, smoking, and use of additional drugs could have also contributed to the observed effect. In addition, previous studies on the effects of methadone on child cognition and brain development have produced varying results [reviewed in 8]. An early analysis of 4-month-old infants born from methadone-maintained women found drug-exposed babies to exhibit poor coordination and to be more tense and active [51]; moreover, while some studies in older children found no differences in mental development $[52,53]$, others reported lower performance and intelligence $[54,55]$.

Regardless of the final outcome, and far from beneficial, accelerated or increased myelination at an earlier age as observed in the present study could potentially disrupt normal connectivity in the developing brain. Developmental myelination is highly synchronized with CNS plasticity and neuronal network organization, and thus it is conceivable that neurological dysfunction could also result from precocious increased myelin formation. While accelerated myelination in the developing human brain has been poorly investigated, such a situation is known to occur in children with hemimegalencephaly $[56,57]$, following increased neuronal activity associated to epilepsy $[57,58]$, and in Sturge-Weber syndrome, a congenital condition linked to a variety of symptoms including among others seizures, visual deficits, and cognitive impairment [59]. In this regard, a recent study demonstrated that maturation of the rat striatum is accompanied by a well-defined developmental switch in the activity of complex gene networks which culminate with the expression of myelin-related genes [60]. Based on those findings and the fact that striatal neurons integrate information from multiple brain regions, the authors 
suggested that alterations in the temporal expression of genes associated with myelination could underlie different neuropsychiatric disorders. Important in this regard are previous studies from Robinson et al. [61] indicating that the striatum of methadone-exposed pups exhibited increased acetylcholine turnover rates, though a correlation with the present observations on myelination remains undetermined.

The present findings demonstrate direct effects of methadone on oligodendrocytes. However, opioid receptors are known to be ubiquitously expressed in both neuronal and glial populations and thus it is plausible that the in vivo effects on myelination detected in this study as well as those previously observed in pups exposed to buprenorphine [31] may in addition reflect indirect actions mediated by other cells. Rat brain levels of the $\mu$ - and $\delta$-opioid receptor agonist $\beta$-endorphine are elevated at embryonic and postnatal ages that coincide with periods of proliferative activity of both neuronal and glial progenitors [62]. Prolonged administration of morphine to neonatal rats was shown to be associated with increased neuronal apoptosis in selective areas of the brain [63], and morphine exposure in adolescent rats results in increased Toll-like receptor 4 signaling and microglial activation [64]. Furthermore, different lines of evidence indicate that endogenous opioids control the proliferation and differentiation of astrocytes $[65,66]$, cells that could potentially exert both positive and negative effects on oligodendrocytes and myelination [recently reviewed in 67]. Interestingly, we have previously observed that, regardless of the dose, perinatal exposure to buprenorphine results in an increased caliber of myelinated axons and disproportionally thinner myelin sheaths, a situation that may indicate alterations at the level of axon-oligodendroglial/myelin interactions [31]. The finding that such an abnormal correlation of myelin thickness and axonal caliber was not detected by the present studies in the pups exposed to methadone further emphasizes the complexity and variety of the opioid effects on the developing brain.

Regardless of the mechanism and beyond the impact of methadone on the fetal and newborn brain, the present findings also raise the important possibility of myelinrelated effects in adolescents and young adults, high-risk groups for both prescription and nonprescription opioid abuse $[1,68,69]$. This is because early and late adolescence are highly vulnerable periods of later brain development that are accompanied by substantial myelin formation [70-72]. Notably, extensive myelination during adolescence and young adulthood is known to occur in the prefrontal cortex $[70,71,73]$, a higher-order region involved in complex cognitive executive function [7476]. Furthermore, the relevance of myelin deposition at this later phase of brain maturation is evidenced by a number of psychiatric disorders, the onset of which correlates with white matter pathology during adolescence, including, among others, schizophrenia [77-82] and bipolar disorder [77, 83, 84]. It should also be considered that the possibility of interference with late myelination extends beyond opioid abuse and opioid detoxification treatments and could be particularly important in the case of patients within this age bracket subjected to frequent opioid treatments for pain relief. Such is the case of severe-pain management in sickle cell disease, in which patients are commonly prescribed opioid medications including morphine, methadone, and oxycodone [85].

Taken together, the present study and our previous findings on buprenorphine $[22,31]$ underscore the importance of the endogenous opioid system in the control of oligodendrocyte development and myelin formation. These observations raise the possibility of deleterious effects of opioid use at critical stages of myelination. Further understanding of the molecular and cellular mechanisms mediating these events should be crucial to the elaboration of therapies minimizing long-term effects on brain development and cognition.

\section{Acknowledgments}

This work was supported by NIH grant R21DA027099-01 and NIH CTSA grant UL1TR000058 from the Virginia Commonwealth University (VCU) Center for Clinical and Translational Research. Microscopy was performed at the VCU Department of Anatomy and Neurobiology Microscopy Facility, supported in part by funding from NIH-NINDS Center core grant 5P30NS047463. The authors wish to thank Mrs. Judy Williamson for the preparation of samples for electron microscopic examination.

References

$$
\begin{aligned}
& \text { Degenhardt L, Whiteford HA, Ferrari AJ, } \\
& \text { Baxter AJ, Charlson FJ, Hall WD, Freedman } \\
& \text { G, Burstein R, Johns N, Engell RE, Flaxman } \\
& \text { A, Murray CJ, Vos T: Global burden of disease } \\
& \text { attributable to illicit drug use and depen- } \\
& \text { dence: findings from the Global Burden of } \\
& \text { Disease Study 2010. Lancet 2013;382:1564- } \\
& \text { 1574. } \\
& \text { Kroon JS, Wohlfarth TD, Dieleman J, Sutter- } \\
& \text { land AL, Storosum JG, Denys D, de Haan L, } \\
& \text { Sturkenboom MC: Incidence rates and risk } \\
& \text { factors of bipolar disorder in the general pop- } \\
& \text { ulation: a population-based cohort study. Bi- } \\
& \text { polar Disord 2013;15:306-313. }
\end{aligned}
$$


- 3 Sutterland AL, Dieleman J, Storosum JG, Voordouw BA, Kroon J, Veldhuis J, Denys DA, de Haan L, Sturkenboom MC: Annual incidence rate of schizophrenia and schizophrenia spectrum disorders in a longitudinal population-based cohort study. Soc Psychiatry Psychiatr Epidemiol 2013;48:13571365.

4 Welle-Strand GK, Skurtveit S, Jones HE, Waal H, Bakstad B, Bjarko L, Ravndal E: Neonatal outcomes following in utero exposure to methadone or buprenorphine: a national cohort study of opioid-agonist treatment of pregnant women in Norway from 1996 to 2009. Drug Alcohol Depend 2013;127:200206.

5 Minozzi S, Amato L, Bellisario C, Ferri M, Davoli M: Maintenance agonist treatments for opiate-dependent pregnant women. Cochrane Database Syst Rev 2013;12:CD006318.

-6 Nanovskaya T, Deshmukh S, Brooks M, Ahmed MS: Transplacental transfer and metabolism of buprenorphine. J Pharmacol Exp Ther 2002;300:26-33.

7 Nekhayeva IA, Nanovskaya TN, Deshmukh SV, Zharikova OL, Hankins GD, Ahmed MS Bidirectional transfer of methadone across human placenta. Biochem Pharmacol 2005; 69:187-197.

8 Konijnenberg C, Melinder A: Prenatal exposure to methadone and buprenorphine: a review of the potential effects on cognitive development. Child Neuropsychol 2011;17: 495-519.

9 Yin X, Crawford TO, Griffin JW, Tu P, Lee VM, Li C, Roder J, Trapp BD: Myelin-associated glycoprotein is a myelin signal that modulates the caliber of myelinated axons. J Neurosci 1998;18:1953-1962.

10 Rasband MN, Trimmer JS: Developmental clustering of ion channels at and near the node of Ranvier. Dev Biol 2001;236:5-16.

11 Ransom BR, Kettenmann H: Electrical coupling, without dye coupling, between mammalian astrocytes and oligodendrocytes in cell culture. Glia 1990;3:258-266.

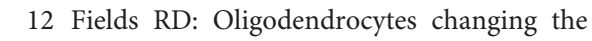
rules: action potentials in glia and oligodendrocytes controlling action potentials. Neuroscientist 2008;14:540-543.

13 Saab AS, Tzvetanova ID, Nave KA: The role of myelin and oligodendrocytes in axonal energy metabolism. Curr Opin Neurobiol 2013; 23:1065-1072.

14 Morrison BM, Lee Y, Rothstein JD: Oligodendroglia: metabolic supporters of axons. Trends Cell Biol 2013;23:644-651.

15 LeVine SM, Goldman JE: Spatial and temporal patterns of oligodendrocyte differentiation in rat cerebrum and cerebellum. J Comp Neurol 1988;277:441-455.

16 Vogel US, Reynolds R, Thompson RJ, Wilkin GP: Expression of the 2', $3^{\prime}$-cyclic nucleotide $3^{\prime}$-phosphohydrolase gene and immunoreactive protein in oligodendrocytes as revealed by in situ hybridization and immunofluorescence. Glia 1988;1:184-190.
17 Warf BC, Fok-Seang J, Miller RH: Evidence for the ventral origin of oligodendrocyte precursors in the rat spinal cord. J Neurosci 1991; 11:2477-2488.

18 Mitew S, Hay CM, Peckham H, Xiao J, Koenning M, Emery B: Mechanisms regulating the development of oligodendrocytes and central nervous system myelin. Neuroscience 2013, DOI: 10.1016/j.neuroscience.2013.11.029.

19 Knapp PE, Maderspach K, Hauser KF: Endogenous opioid system in developing normal and jimpy oligodendrocytes: $\mathrm{mu}$ and kappa opioid receptors mediate differential mitogenic and growth responses. Glia 1998; 22:189-201

20 Hahn JW, Jagwani S, Kim E, Rendell VR, He J, Ezerskiy LA, Wesselschmidt R, Coscia CJ, Belcheva MM: Mu and kappa opioids modulate mouse embryonic stem cell-derived neural progenitor differentiation via map kinases. J Neurochem 2010;112:1431-1441.

21 Persson AI, Bull C, Eriksson PS: Requirement for Id 1 in opioid-induced oligodendrogenesis in cultured adult rat hippocampal progenitors. Eur J Neurosci 2006;23:2277-2288.

22 Eschenroeder AC, Vestal-Laborde AA, Sanchez ES, Robinson SE, Sato-Bigbee C: Oligodendrocyte responses to buprenorphine uncover novel and opposing roles of mu-opioidand nociceptin/orphanin FQ receptors in cell development: implications for drug addiction treatment during pregnancy. Glia 2012;60: 125-136.

23 Unick GJ, Rosenblum D, Mars S, Ciccarone D: Intertwined epidemics: national demographic trends in hospitalizations for heroinand opioid-related overdoses, 1993-2009. PLoS One 2013;8:e54496.

24 Calcaterra S, Glanz J, Binswanger IA: National trends in pharmaceutical opioid related overdose deaths compared to other substance related overdose deaths: 1999-2009. Drug Alcohol Depend 2013;131:263-270.

25 Compton WM, Volkow ND: Major increases in opioid analgesic abuse in the United States: concerns and strategies. Drug Alcohol Depend 2006;81:103-107.

26 Voon P, Kerr T: 'Nonmedical' prescription opioid use in North America: a call for priority action. Subst Abuse Treat Prev Policy 2013;8:39.

27 Wolters EC, van Wijngaarden GK, Stam FC, Rengelink H, Lousberg RJ, Schipper ME, Verbeeten B: Leucoencephalopathy after inhaling 'heroin' pyrolysate. Lancet 1982;2:1233-1237.

28 Weber W, Henkes H, Moller P, Bade K, Kuhne D: Toxic spongiform leucoencephalopathy after inhaling heroin vapour. Eur Radiol 1998;8:749-755.

29 Chen CY, Lee KW, Lee CC, Chin SC, Chung HW, Zimmerman RA: Heroin-induced spongiform leukoencephalopathy: value of diffusion MR imaging. J Comput Assist Tomogr 2000;24:735-737.

30 Nanan R, von Stockhausen HB, Petersen B, Solymosi L, Warmuth-Metz M: Unusual pattern of leukoencephalopathy after morphine sulphate intoxication. Neuroradiology 2000; 42:845-848.

- 31 Sanchez ES, Bigbee JW, Fobbs W, Robinson SE, Sato-Bigbee C: Opioid addiction and pregnancy: perinatal exposure to buprenorphine affects myelination in the developing brain. Glia 2008;56:1017-1027.

32 Baxter LE Sr, Campbell A, Deshields M, Levounis P, Martin JA, McNicholas L, Payte JT, Salsitz EA, Taylor T, Wilford BB: Safe methadone induction and stabilization: report of an expert panel. J Addict Med 2013;7:377-386.

33 Robinson SE: Effects of perinatal buprenorphine and methadone exposures on striatal cholinergic ontogeny. Neurotoxicol Teratol 2002;24:137-142.

34 Colello RJ, Sato-Bigbee C: Purification of oligodendrocytes and their progenitors using immunomagnetic separation and Percoll gradient centrifugation. Curr Protoc Neurosci 2001, DOI: 10.1002/0471142301.ns0312s03.

-35 Saini HS, Coelho RP, Goparaju SK, Jolly PS, Maceyka M, Spiegel S, Sato-Bigbee C: Novel role of sphingosine kinase 1 as a mediator of neurotrophin-3 action in oligodendrocyte progenitors. J Neurochem 2005;95:1298-1310.

36 Coelho RP, Yuelling LM, Fuss B, Sato-Bigbee C: Neurotrophin-3 targets the translational initiation machinery in oligodendrocytes. Glia 2009;57:1754-1764

37 Coelho RP, Payne SG, Bittman R, Spiegel S, Sato-Bigbee C: The immunomodulator FTY720 has a direct cytoprotective effect in oligodendrocyte progenitors. J Pharmacol Exp Ther 2007;323:626-635.

- 38 Workman AD, Charvet CJ, Clancy B, Darlington RB, Finlay BL: Modeling transformations of neurodevelopmental sequences across mammalian species. J Neurosci 2013;33:7368-7383.

39 Evans CA, Jolivette LJ, Nagilla R, Ward KW: Extrapolation of preclinical pharmacokinetics and molecular feature analysis of 'discovery-like' molecules to predict human pharmacokinetics. Drug Metab Dispos 2006;34: 1255-1265.

40 de Castro A, Jones HE, Johnson RE, Gray TR, Shakleya DM, Huestis MA: Maternal methadone dose, placental methadone concentrations, and neonatal outcomes. Clin Chem 2011;57:449-458.

41 de Ferra F, Engh H, Hudson L, Kamholz J, Puckett C, Molineaux S, Lazzarini RA: Alternative splicing accounts for the four forms of myelin basic protein. Cell 1985;43:721-727.

42 Baumann N, Pham-Dinh D: Biology of oligodendrocyte and myelin in the mammalian central nervous system. Physiol Rev 2001;81: 871-927.

43 Readhead C, Takasashi N, Shine HD, Saavedra R, Sidman R, Hood L: Role of myelin basic protein in the formation of central nervous system myelin. Ann NY Acad Sci 1990;605: 280-285.

44 Norton WT, Poduslo SE: Myelination in rat brain: changes in myelin composition during brain maturation. J Neurochem 1973;21:759773. 
-45 Sato-Bigbee C, Pal S, Chu AK: Different neuroligands and signal transduction pathways stimulate CREB phosphorylation at specific developmental stages along oligodendrocyte differentiation. J Neurochem 1999;72:139147.

-46 Knapp PE, Hauser KF: Mu-opioid receptor activation enhances DNA synthesis in immature oligodendrocytes. Brain Res 1996;743: 341-345.

-47 Alvarez VA, Arttamangkul S, Dang V, Salem A, Whistler JL, Von Zastrow M, Grandy DK, Williams JT: Mu-opioid receptors: ligand-dependent activation of potassium conductance, desensitization, and internalization. J Neurosci 2002;22:5769-5776.

48 Bodnar RJ, Kest B: Sex differences in opioid analgesia, hyperalgesia, tolerance and withdrawal: central mechanisms of action and roles of gonadal hormones. Horm Behav 2010;58:72-81.

-49 Cerghet M, Skoff RP, Swamydas M, Bessert D: Sexual dimorphism in the white matter of rodents. J Neurol Sci 2009;286:76-80.

-50 Walhovd KB, Watts R, Amlien I, Woodward LJ: Neural tract development of infants born to methadone-maintained mothers. Pediatr Neurol 2012;47:1-6.

51 Bernstein V, Jeremy RJ, Hans SL, Marcus J: A longitudinal study of offspring born to methadone-maintained women. 2. Dyadic interaction and infant behavior at 4 months. Am J Drug Alcohol Abuse 1984;10:161-193.

52 Hans SL: Developmental consequences of prenatal exposure to methadone. Ann NY Acad Sci 1989;562:195-207.

53 de Cubas MM, Field T: Children of methadone-dependent women: developmental outcomes. Am J Orthopsychiatry 1993;63:266276.

54 Bauman PS, Levine SA: The development of children of drug addicts. Int J Addict 1986;21: 849-863.

-55 van Baar AL, Soepatmi S, Gunning WB, Akkerhuis GW: Development after prenatal exposure to cocaine, heroin and methadone. Acta Paediatr Suppl 1994;404:40-46.

-56 Yagishita A, Arai N, Tamagawa K, Oda M: Hemimegalencephaly: signal changes suggesting abnormal myelination on MRI. Neuroradiology 1998;40:734-738.

57 Goldsberry G, Mitra D, MacDonald D, Patay $\mathrm{Z}$ : Accelerated myelination with motor system involvement in a neonate with immediate postnatal onset of seizures and hemimegalencephaly. Epilepsy Behav 2011;22:391-394.

58 Duprez T, Ghariani S, Grandin C, Smith AM, Gadisseux JF, Evrard P: Focal seizure-induced premature myelination: speculation from serial MRI. Neuroradiology 1998;40:580-582.

-59 Adamsbaum C, Pinton F, Rolland Y, Chiron C, Dulac O, Kalifa G: Accelerated myelination in early Sturge-Weber syndrome: MRISPECT correlations. Pediatr Radiol 1996;26: 759-762.

-60 Novak G, Fan T, O’Dowd BF, George SR: Striatal development involves a switch in gene ex- pression networks, followed by a myelination event: implications for neuropsychiatric disease. Synapse 2013;67:179-188.

61 Robinson SE, Guo H, Maher JR, McDowell KP, Kunko PM: Postnatal methadone exposure doe not prevent prenatal methadone-induced changes in striatal cholinergic neurons. Brain Res Dev Brain Res 1996;95:118-121.

62 Angelogianni P, Li HL, Gianoulakis C: Ontogenesis of proopiomelanocortin and its processing to beta-endorphin by the fetal and neonatal rat brain. Neuroendocrinology 2000;72:231-241.

63 Bajic D, Commons KG, Soriano SG: Morphine-enhanced apoptosis in selective brain regions of neonatal rats. Int J Dev Neurosci 2013;31:258-266.

64 Schwarz JM, Bilbo SD: Adolescent morphine exposure affects long-term microglial function and later-life relapse liability in a model of addiction. J Neurosci 2013;33:961-971.

65 Hauser KF, Stiene-Martin A: Characterization of opioid-dependent glial development in dissociated and organotypic cultures of mouse central nervous system: critical periods and target specificity. Brain Res Dev Brain Res 1991;62:245-255.

66 Stiene-Martin A, Knapp PE, Martin K, Gurwell JA, Ryan S, Thornton SR, Smith FL, Hauser KF: Opioid system diversity in developing neurons, astroglia, and oligodendroglia in the subventricular zone and striatum: Impact on gliogenesis in vivo. Glia 2001;36:7888.

67 Lundgaard I, Osorio MJ, Kress BT, Sanggaard $\mathrm{S}$, Nedergaard M: White matter astrocytes in health and disease. Neuroscience 2013, DOI: 10.1016/j.neuroscience.2013.10.050.

68 Whiteside LK, Walton MA, Bohnert AS, Blow FC, Bonar EE, Ehrlich P, Cunningham RM: Nonmedical prescription opioid and sedative use among adolescents in the emergency department. Pediatrics 2013;132:825-832.

69 McCabe SE, West BT, Boyd CJ: Medical use, medical misuse, and nonmedical use of prescription opioids: results from a longitudinal study. Pain 2013;154:708-713.

70 Pfefferbaum A, Mathalon DH, Sullivan EV, Rawles JM, Zipursky RB, Lim KO: A quantitative magnetic resonance imaging study of changes in brain morphology from infancy to late adulthood. Arch Neurol 1994;51:874887.

71 Qiu D, Tan LH, Zhou K, Khong PL: Diffusion tensor imaging of normal white matter maturation from late childhood to young adulthood: voxel-wise evaluation of mean diffusivity, fractional anisotropy, radial and axial diffusivities, and correlation with reading development. Neuroimage 2008;41:223-232.

72 Whitaker KJ, Kolind SH, MacKay AL, Clark CM: Quantifying development: investigating highly myelinated voxels in preadolescent corpus callosum. Neuroimage 2008; $43: 731-$ 735 .

73 Barnea-Goraly N, Menon V, Eckert M, Tamm L, Bammer R, Karchemskiy A, Dant CC, Reiss
AL: White matter development during childhood and adolescence: a cross-sectional diffusion tensor imaging study. Cereb Cortex 2005; $15: 1848-1854$

74 Fuster JM: The prefrontal cortex - an update: time is of the essence. Neuron 2001;30:319333.

75 Miller EK, Cohen JD: An integrative theory of prefrontal cortex function. Annu Rev Neurosci 2001;24:167-202.

76 Wood JN, Grafman J: Human prefrontal cortex: processing and representational perspectives. Nat Rev Neurosci 2003;4:139-147.

77 Chambers JS, Perrone-Bizzozero NI: Altered myelination of the hippocampal formation in subjects with schizophrenia and bipolar disorder. Neurochem Res 2004;29:22932302.

78 Kubicki M, Park H, Westin CF, Nestor PG, Mulkern RV, Maier SE, Niznikiewicz M, Connor EE, Levitt JJ, Frumin M, Kikinis R, Jolesz FA, McCarley RW, Shenton ME: DTI and MTR abnormalities in schizophrenia: analysis of white matter integrity. Neuroimage 2005;26:1109-1118.

79 Whitford TJ, Kubicki M, Schneiderman JS, O’Donnell LJ, King R, Alvarado JL, Khan U, Markant D, Nestor PG, Niznikiewicz M, McCarley RW, Westin CF, Shenton ME: Corpus callosum abnormalities and their association with psychotic symptoms in patients with schizophrenia. Biol Psychiatry 2010;68:7077.

80 Kerns D, Vong GS, Barley K, Dracheva S, Katsel P, Casaccia P, Haroutunian V, Byne W: Gene expression abnormalities and oligodendrocyte deficits in the internal capsule in schizophrenia. Schizophr Res 2010;120:150158.

81 Walterfang M, Wood SJ, Velakoulis D, Copolov D, Pantelis C: Diseases of white matter and schizophrenia-like psychosis. Aust NZ J Psychiatry 2005;39:746-756.

82 Roussos P, Haroutunian V: Schizophrenia: susceptibility genes and oligodendroglial and myelin related abnormalities. Front Cell Neurosci 2014;8:5.

83 Brambilla P, Bellani M, Yeh PH, Soares JC, Tansella M: White matter connectivity in bipolar disorder. Int Rev Psychiatry 2009;21: 380-386.

84 Mahon K, Burdick KE, Szeszko PR: A role for white matter abnormalities in the pathophysiology of bipolar disorder. Neurosci Biobehav Rev 2010;34:533-554.

85 Dampier CD, Smith WR, Kim HY, Wager CG, Bell MC, Minniti CP, Keefer J, Hsu L, Krishnamurti L, Mack AK, McClish D, McKinlay SM, Miller ST, Osunkwo I, Seaman P, Telen MJ, Weiner DL; Investigators of the Sickle Cell Disease Clinical Research Network: Opioid patient controlled analgesia use during the initial experience with the IMPROVE PCA trial: a phase III analgesic trial for hospitalized sickle cell patients with painful episodes. Am J Hematol 2011; 86:E70-E73. 